\title{
EXPERIMENTAL DETERMINATION OF THE VOID VOLUME FRACTION FOR S235JR STEEL AT FAILURE IN THE RANGE OF HIGH STRESS TRIAXIALITIES
}

\begin{abstract}
This paper is concerned with the critical void volume fraction $f_{F}$ representing the size of microdefects in a material at the time of failure. The parameter is one of the constants of the Gurson-Tvergaard-Needleman (GTN) material model that need to be determined while modelling material failure processes. In this paper, an original experimental method is proposed to determine the values of $f_{F}$. The material studied was S235JR steel. After tensile tests, the void volume fraction was measured at the fracture surface using an advanced technique of quantitative image analysis The material was subjected to high initial stress triaxialities $T_{0}$ ranging from 0.556 to 1.345 . The failure processes in S235JR steel were analysed taking into account the influence of the state of stress.

Keywords: failure, critical void volume fraction $f_{F}$, Gurson-Tvergaard-Needleman material model, S235JR steel, high stress triaxiality.
\end{abstract}

\section{Introduction}

For many metals, failure is closely linked with the processes that take place in their microstructure. The knowledge of the phenomena is essential to model the material failure. This is particularly important in the case of structural steels used for engineering purposes as the information helps predict the time of failure of an entire structure.

Microstructural observations of the failure processes in many metallic materials reveal that there are three major mechanisms of fracture: brittle fracture, shear fracture and ductile fracture. Ductile fracture is typical of basic structural steels used in civil engineering. The failure phenomena are due to the presence of microstructural defects in the form of voids, as shown schematically in Fig. 1.

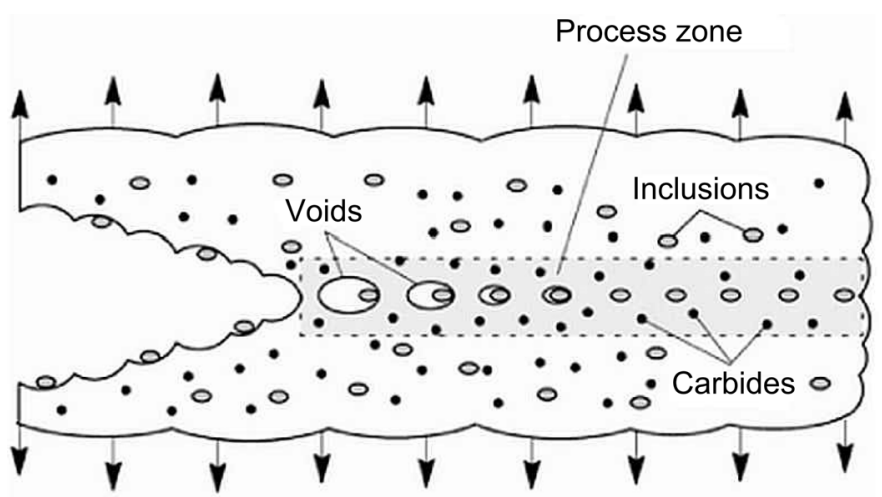

Fig. 1. Formation of microdefects in a material undergoing ductile fracture (based on [1])
During deformation, voids form at inclusions and precipitates because their stiffness is higher than that of the matrix. The failure of the material is thus dependent on the void growth, which is the most important phenomenon observed during the damage processes taking place in the material microstructure.

The formation of microdefects has influence on the material behaviour in the macroscale causing, for instance, a decrease in the material strength (see the stress-strain $\sigma(\varepsilon)$ curve in Fig 2).

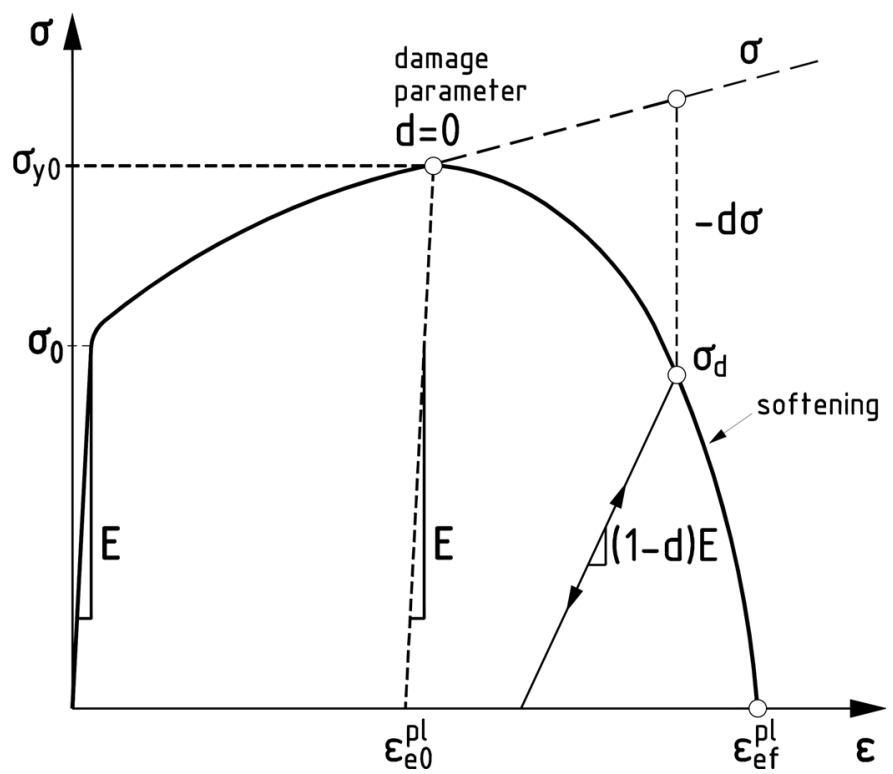

Fig. 2. Decrease in the strength of the material due to the growth of microstructural defects described by the damage parameter $d$ [2]

\footnotetext{
* KIELCE UNIVERSITY OF TECHNOLOGY, 7. TYSIACLLECIA PAŃSTWA POLSKIEGO AL., 25-314 KIELCE, POLAND

\# Corresponding author: kossak@tu.kielce.pl
} 
After the stress reaches a maximum, it begins to drop and necking is observed. Simultaneously, there is a significant rise in the void growth rate resulting in an increase in the volume of microdefects [3-4]. The prevailing state of stress also changes, especially when the stress triaxialities are high. These phenomena have been described by researchers looking for a measurable parameter to determine the relationship between the formation of microdefects and the reduction in stress $\sigma$ in the material. According to the most general approach, the influence of the defect formation on the material strength can be described using the damage parameter $d$; it is written as a general formula: $\sigma_{d}=\sigma(1-d)$. As can be seen, the values of stress determined by taking into account microdefects $\left(\sigma_{d}\right)$ are much lower than those determined using the assumptions of the continuum mechanics of solids $(\sigma)$. The material fails when the damage defined by the damage parameter $d$ reaches a critical value, i.e. when $d=1$.

Since the effect of microdefects on the material strength at each stage of failure is so clear, it should be taken into consideration in many material models describing the response and behaviour of a material undergoing various deformations until it fractures. For example, Kachanov characterised this phenomenon using the damage parameter, which is defined as the damaged area divided by the unaffected area [5]. Some material models based on failure mechanics were developed later. An original approach was presented in 1977 by Gurson, who linked the material damage with the volume of microdefects characterised by the so-called void volume fraction $f[6]$.

According to this model, a void exists physically in a unit cell of a material, as shown schematically in Fig. 3a. The void volume fraction $f$ is defined as $f=V_{v} / V$, where $V_{v}$ is the volume of the voids and $V$ is the volume of the material. Thus, the void volume fraction $f$ is described as randomly distributed cavities (Fig. 3b).

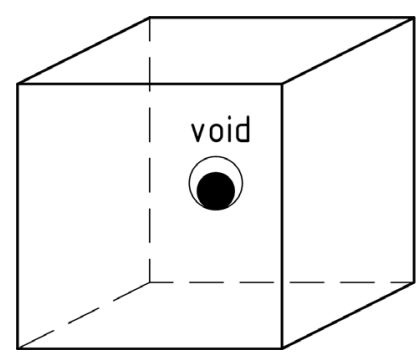

a)

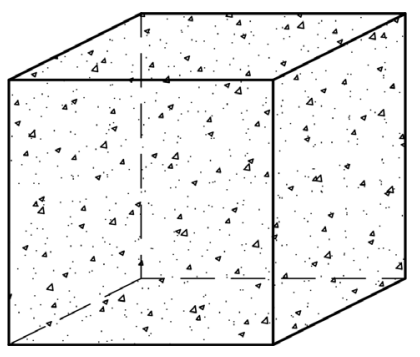

b)
Fig. 3. (a) Microdefect in a material unit cell; (b) randomly distributed cavities representing the void volume fraction $f$ [4]

The original Gurson model was developed by several authors. The major modification was made by Tvergaard and it involved introducing the coefficients $q_{i}$, which define the plastic properties of the material [7]. Then, Tvergaard and Needleman redefined the function of void volume fraction $f$ as $f^{*}$ [8]. Now the Gurson yield function is commonly defined as the GursonTvergaard-Needleman (GNT) material model and it is expressed in the following form:

$$
\Phi=\left(\frac{\sigma_{e}}{\sigma_{0}}\right)^{2}+2 q_{1} f^{*} \cosh \left(-q_{2} \frac{3 \sigma_{m}}{2 \sigma_{0}}\right)-\left(1+q_{3} f^{* 2}\right)=0
$$

where: $\sigma_{e}$ - effective stress defined according to the HuberMises-Hencky strength hypothesis

$$
\sigma_{e}=\frac{1}{\sqrt{2}} \sqrt{\left(\sigma_{1}-\sigma_{2}\right)^{2}+\left(\sigma_{2}-\sigma_{3}\right)^{2}+\left(\sigma_{1}-\sigma_{3}\right)^{2}}
$$

(with $\sigma_{1}, \sigma_{2}, \sigma_{3}$ being the principal stresses), $\sigma_{0}$ - flow stress of the matrix material (yield stress), $\sigma_{m}$ - hydrostatic stress, $f^{*}-$ modified void volume fraction and $q_{i}$ - Tvergaard coefficients.

The typical values of the Tvergaard coefficients used for metallic materials are: $q_{1}=1.5, q_{2}=1.0$ and $q_{3}=q_{1}^{2}=2.25$ [7-9]. For years, the values were treated as constants, which can be easily found in the literature. Then, however, it was revealed that the Tvergaard coefficients were dependent on the elastic and strength properties of the material, i.e. the modulus of elasticity $E$, the yield strength $\sigma_{0}$ and the strain hardening exponent $N[10]$. The values of the Tvergaard coefficients for S235JR steel determined using this assumption are: $q_{1}=1.90, q_{2}=0.81$ and $q_{3}=q_{1}^{2}=3.61$ [4].

The modified void volume fraction $f^{*}$ determines the influence of microdefects on the stress state. While the material undergoes plastic deformation, its value changes according to the following function:

$$
f^{*}=\left\{\begin{array}{lll}
f & \text { for } & f \leq f_{c} \\
f_{c}+\frac{1 / q_{1}-f_{c}}{f_{F}-f_{c}}\left(f-f_{c}\right) & \text { for } & f_{c}<f
\end{array}\right.
$$

where: $f_{c}$ - critical void volume fraction corresponding to the onset of void coalescence, $f_{F}$ - critical void volume fraction corresponding to the material failure.

Tvergaard and Needleman modified the original Gurson function of the void volume fraction $f$ in order to model the material failure for a case when the void volume fraction $f$ is higher than the critical void volume fraction $f_{c}$ until the stress capacity is lost. As can be seen from formula (2), the modified void volume fraction $f^{*}$ changes depending on the relationship between the void volume fraction $f$ and the critical void volume fraction $f_{c}$, with the latter corresponding to the onset of void coalescence. In the range when $f$ is higher than $f_{c}$, the modified void volume fraction $f^{*}$ is a function of the Tvergaard coefficient $q_{1}$ and the critical void volume fractions $f_{c}$ and $f_{F}$.

Tvergaard and Needleman defined $f_{F}$ as the critical void volume fraction at the time of final failure, i.e. when $f=f_{F}[8]$. The critical void volume fraction at the time of failure is one of the GTN parameters that need to be determined to describe the material properties. Its value differs depending on the material structure and the state of stress. Generally, $f_{F}$ is determined by combining experimental and numerical methods [11-15]; the other GTN parameters are defined in a similar way [3,16-18].

Another approach assumes that the critical void volume fraction $f_{F}$ is determined only from experimental results [19-20]. The value of $f_{F}$ is established on the basis of tensile tests measurements of the void volume fraction at the time of failure. This 
procedure was used in this study to determine the critical void volume fraction at final failure $f_{F}$ for S235JR structural steel on the basis of the microstructural analysis. In this paper, the problem is considered for two different scales: micro and macro. The analysis at the microscale refers to the process of formation of microvoids due to deformation (GTN model). Since the state of stress has a considerable effect on the ductile fracture of the material studied, the experiments were conducted under spatial stress conditions. The analysis involved determining the range of high initial stress triaxialities for non-deformed specimens. This is a macroscale problem because the failure processes are referred to stress triaxialities. It should be noted, however, that in this study the stress triaxiality was used as a parameter describing the spatial state of stress observed in the analysed elements and, therefore, it should rather be treated in a general way.

\section{Properties of the material tested}

A common grade of structural steel, i.e. S235JR, was considered in this study. It is a mild, low-carbon steel used in civil engineering for the construction of buildings and non-building structures, for instance, bridges. Its chemical composition is characterised by the maximum content of elements: $\mathrm{C}=0.14 \%$, $\mathrm{Mn}=0.54 \%, \mathrm{Si}=0.17 \%, \mathrm{P}=0.016 \%, \mathrm{~S}=0.026 \%, \mathrm{Cu}=0.29 \%$, $\mathrm{Cr}=0.12 \%, \mathrm{Ni}=0.12 \%, \mathrm{Mo}=0.03 \%, \mathrm{~V}=0.002 \%$ and $\mathrm{N}=0.01 \%$. Large amounts of impurities are observed in the microstructure of S235JR steel.

The mean yield stress of S235JR steel obtained in tensile tests [4] was $R_{0.2}=318 \mathrm{MPa}$, which was much more than the required value for this grade, $R_{e H}=235 \mathrm{MPa}$, according to the PN-EN 10025-2 standard [21]. The mean ultimate tensile stress was $R_{m}=446 \mathrm{MPa}$, while the mean percentage elongation was $A_{t}=33.9 \%$.

\section{Experimental approach to the determination of the critical void volume fraction $f_{F}$ for S235JR steel}

As the state of stress has a considerable effect on the failure processes observed in metals, especially S235JR steel [3,4], it needs to be analysed extensively. The complexity of the problem was determined by the stress triaxiality parameter, $T$, defined as:

$$
T=\frac{\sigma_{m}}{\sigma_{e}}
$$

where: $\sigma_{m}=\left(\sigma_{1}+\sigma_{2}+\sigma_{3}\right) / 3-$ hydrostatic stress, $\sigma_{e}-$ effective stress.

The analysis dealt with high stress triaxialities determined for non-deformed specimens, i.e. those observed in the initial state; hence the index 0 . The initial stress triaxialities $T_{0}$ considered in this study ranged from 0.556 to 1.345 . Obviously, $T$ may change in time as a result of deformation. The changes are dependent on the initial value of stress triaxiality, but this problem is not analysed here.
The first step of the study involved subjecting specimens made of S235JR steel to static tension. The tests were performed on four types of specimens with a circumferential notch, illustrated in Fig. 4.
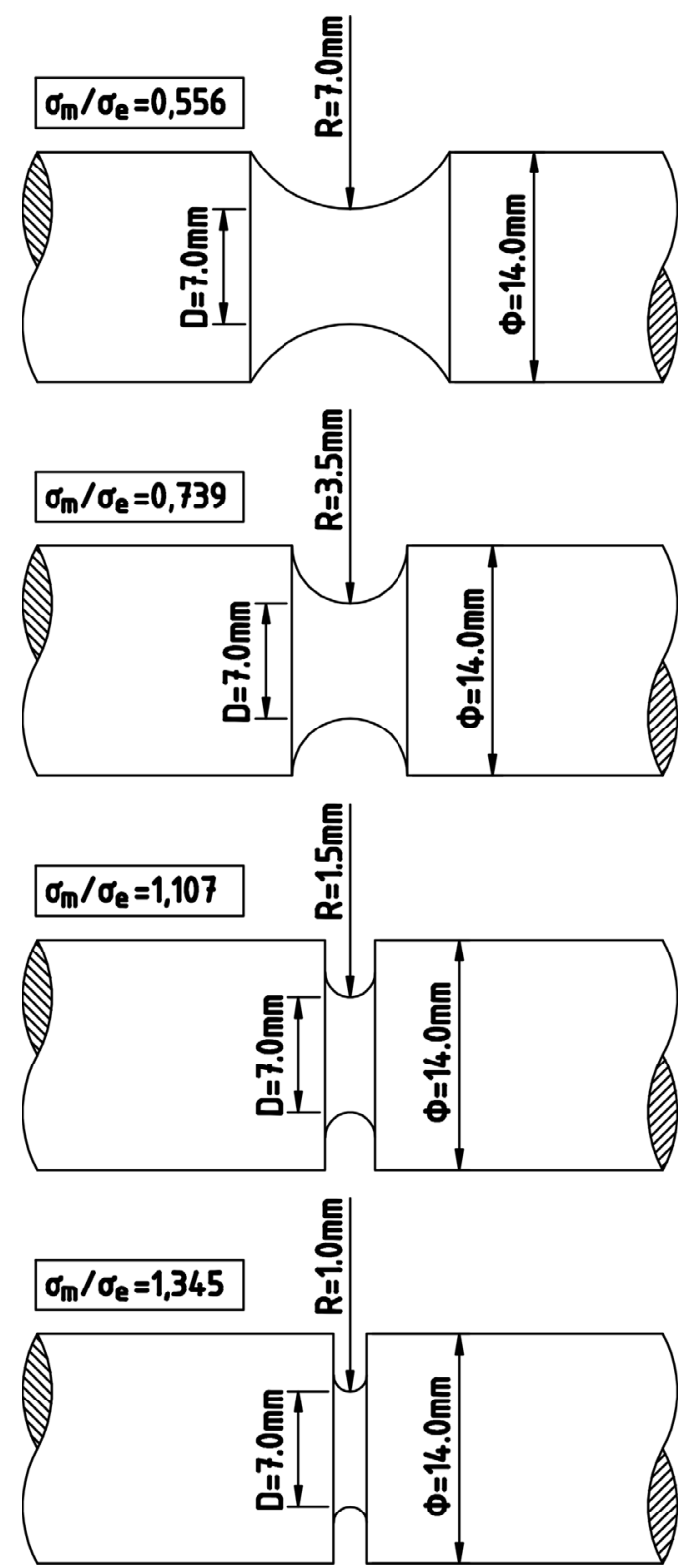

Fig. 4. Geometry of the specimens subjected to static tension under high stress triaxialities

The initial stress triaxialities $T_{0}$ determined for different notch radii $R$ ranged from 0.556 to 1.345 , as shown in Table 1 .

TABLE 1

Initial stress triaxialities $T_{0}$ for the specimens tested

\begin{tabular}{|c|c|}
\hline $\begin{array}{c}\text { Notch radius } \boldsymbol{R} \\
{[\mathbf{m m}]}\end{array}$ & $\begin{array}{c}\text { Initial stress triaxiality } \\
\boldsymbol{T}_{\mathbf{0}}=\boldsymbol{\sigma}_{\boldsymbol{m}} / \boldsymbol{\sigma}_{\boldsymbol{e}}\end{array}$ \\
\hline 7.0 & 0.556 \\
\hline 3.5 & 0.739 \\
\hline 1.5 & 1.107 \\
\hline 1.0 & 1.345 \\
\hline
\end{tabular}


The experimental procedure applied in this study was based on the original assumption of Tvergaard and Needleman, who defined the critical void volume fraction of a material at the time of failure $f_{F}$. Its values were determined from the results of tensile tests conducted for $\mathrm{U}$-notched round specimens subjected to tension until decohesion occurred.

The fracture surfaces shown in Fig. 5 were analysed in order to calculate the void volume fraction at the time of failure, with the value corresponding to the parameter $f_{F}$.

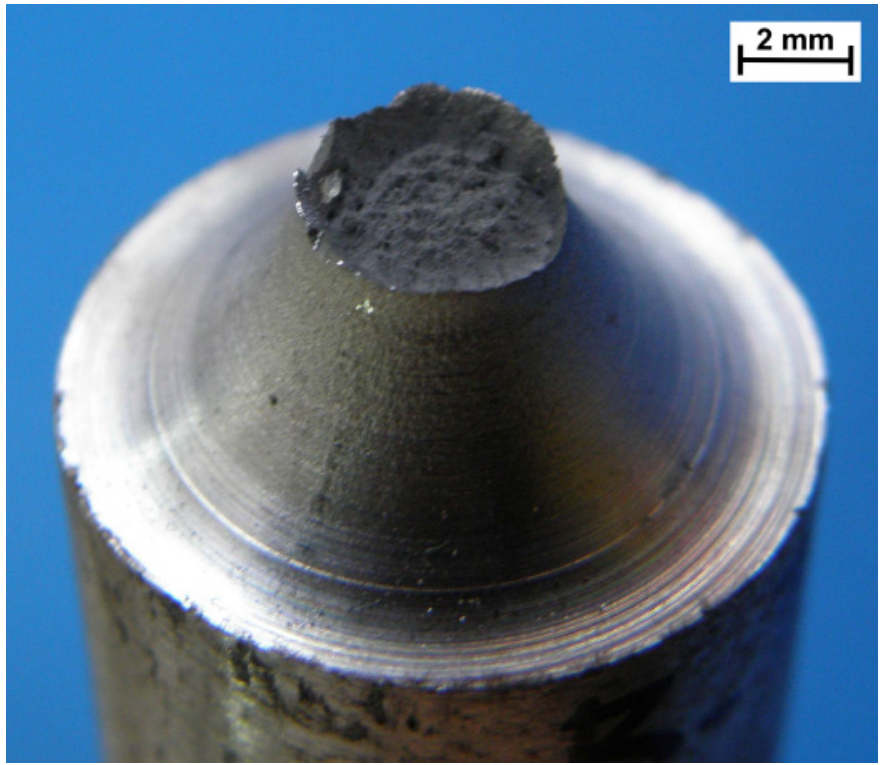

Fig. 5. Fracture surface of a tensile specimen made of S235JR steel

The values of $f_{F}$ were determined by analysing microscopically the fracture surfaces of all the specimens (Fig. 4) at magnifications ranging from $\times 500$ to $\times 5000$. The view of a fracture surface in Fig. 6 indicates that S235JR steel underwent ductile fracture.

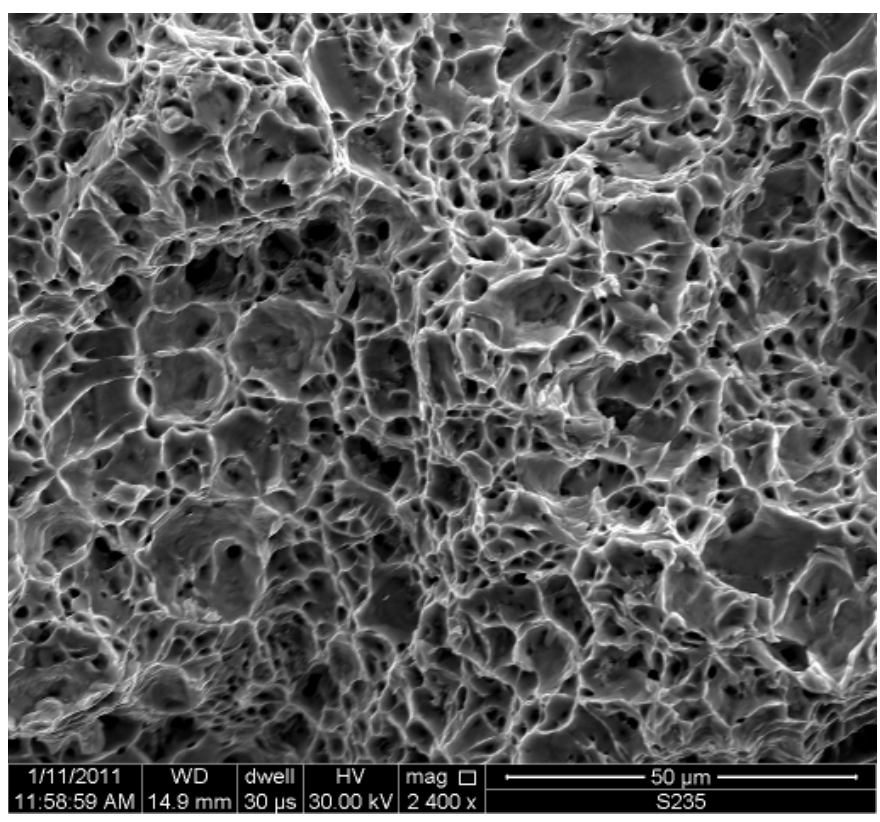

Fig. 6. Fracture surface of S235JR steel
The investigations concerning the critical void volume fraction $f_{F}$ were carried out using the methods of quantitative image analysis. The images of the fracture surfaces were processed to identify the areas covered by voids at the time of material decohesion. The brightest areas in Fig. 6 show the intervoid ligaments that formed before failure. To isolate the void-covered regions, it was necessary to convert the photographs into two colour images. The greyscale was applied as a criterion. The photographs were first binarised to select the brightest areas representing the intervoid ligaments; then, the darker areas (voids) were removed. The image of the intervoid ligaments are shown in Fig. 7.

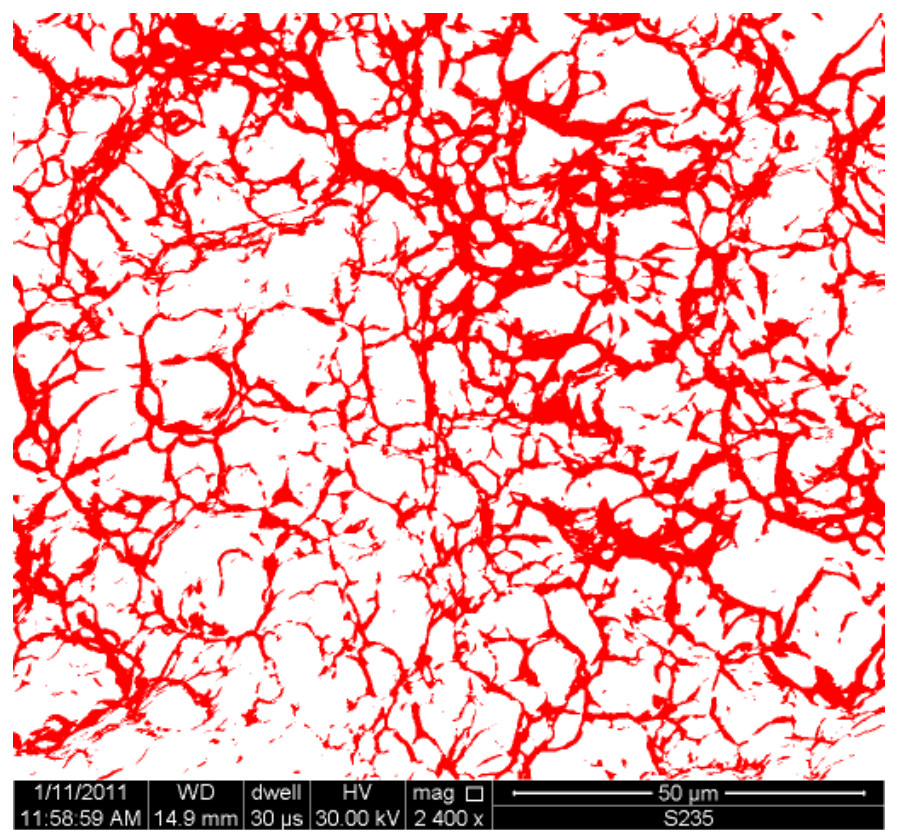

Fig. 7. Binarised fracture surface of S235JR steel

From the images it was possible to calculate the surface area of the white regions representing the voids. The result divided by the total surface area of the images gave the void volume fraction $f_{F}$ at the time of failure.

As mentioned above, the analysis also involved determining the initial stress triaxialities $\left(T_{0}=0.556-1.345\right) .120$ regions of fracture surfaces on 30 specimens were measured for each value of $T_{0}$ (each specimen type). The outliers were rejected using Chauvenet's criterion.

\section{Results and discussion}

The analysis of the results consisted in determining the critical void volume fraction $f_{F}$ at the time of failure for S35JR steel subjected to high triaxial stresses. The values of $f_{F}$ obtained for different values of the parameter $T_{0}$ are provided in Table 2 .

The values of the parameter $f_{F}$ for all the analysed specimens are high; they range from 0.696507 to 0.773543 . They are similar but slightly higher than the typical value, i.e. $f_{F}=0.667$, used for many metals, including the steel considered in this paper $[3,17,18]$. The obtained results are also higher than those 
reported in many studies concerning the GTN material model, i.e. $f_{F}=0.15-0.25[8,12-14]$.

TABLE 2

Critical void volume fractions $f_{F}$ for different initial stress triaxialities $T_{0}$

\begin{tabular}{|c|c|}
\hline \hline $\begin{array}{c}\text { Initial stress triaxiality } \\
\boldsymbol{T}_{\mathbf{0}}=\boldsymbol{\sigma}_{\boldsymbol{m}} / \boldsymbol{\sigma}_{\boldsymbol{e}}\end{array}$ & $\begin{array}{c}\text { Critical void volume } \\
\text { fraction } \boldsymbol{f}_{\boldsymbol{F}}\end{array}$ \\
\hline 1.345 & 0.773543 \\
\hline 1.107 & 0.744157 \\
\hline 0.739 & 0.700713 \\
\hline 0.556 & 0.696507 \\
\hline
\end{tabular}

Another issue is the relationship between the critical void volume fraction $f_{F}$ and the prevailing stress intensity. The values of $f_{F}$ are the lowest for the lowest initial stress triaxialities considered in this study, i.e. $T_{0}=0.556$, and they increase with increasing $T_{0}$. As shown in Fig. 8, two regions of $f_{F}\left(T_{0}\right)$ can be distinguished in the analysed range of the parameter $T_{0}$ In one region, $T_{0}<0.739$. When $T_{0}=0.739$, there is a change in $f_{F}\left(T_{0}\right)$. In the other region, i.e. when $T_{0}=0.739-1.345$, the relationship $f_{F}\left(T_{0}\right)$ is linear.

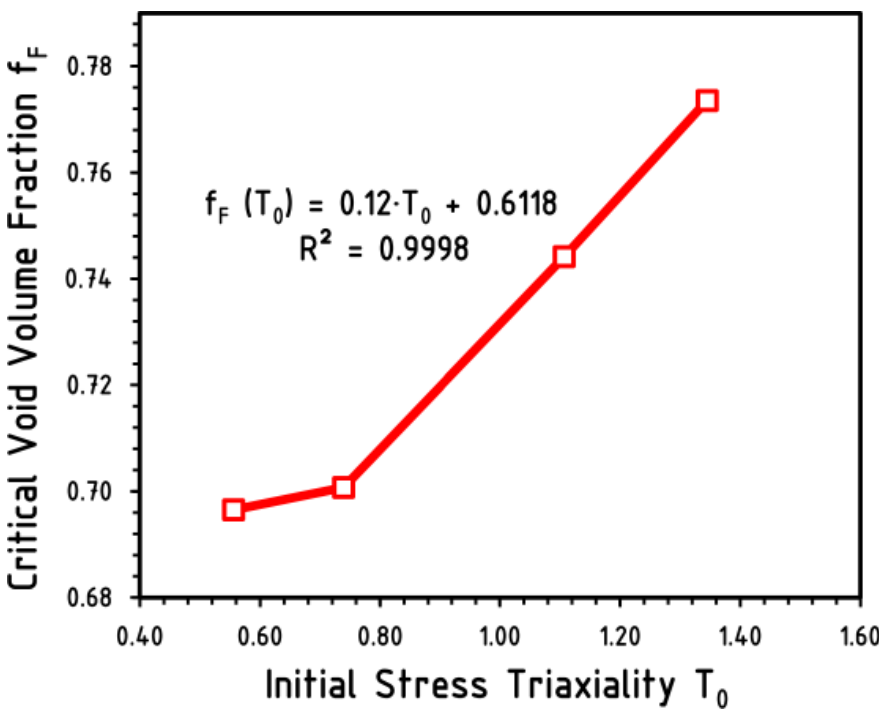

Fig. 8. Critical Void Volume Fraction $f_{F}$ versus Initial Stress Triaxiality $T_{0}$ curve for S235JR steel

This relationship can be expressed as an approximation function:

$$
f_{F}\left(T_{0}\right)=0.12 \cdot T_{0}+0.6188
$$

It should be noted that the above relationship refers to the initial stress triaxialities, i.e. the state when the elements are not loaded. The process of deformation causes the element to change at the macroscale. The naturally occurring changes in the stress state are not the same as those reported for the material described by the GTN model at the microscale. The values of $f_{F}$ are also expected to be different for time-dependent stress triaxialities. This problem was not considered in this study; being complex, it needs further investigation.

\section{Conclusions}

The following conclusions can be drawn from the research presented in this paper:

- the values of the critical void volume fraction $f_{F}$ ranged from 0.696507 to 0.773543 , depending on the prevailing state of stress; they were close to and slightly higher than the typical value, i.e. $f_{F}=0.667$;

- there is a relationship between the parameter $f_{F}$ and the initial stress triaxility $T_{0}$; the higher the values of $T_{0}$, the higher the values of $f_{F}$;

- the linear relationship $f_{F}\left(T_{0}\right)$ for $T_{0}=0.739-1.345$ can be represented by the approximation function $f_{F}\left(T_{0}\right)=$ $0.12 \cdot T_{0}+0.6118$, provided that the relationship was determined for initial stress triaxialities not taking into account the changes in the state of stress resulting from time-dependent deformations.

\section{REFERENCES}

[1] C. Ruggieri, Numerical investigation of constraint effects on ductile fracture in tensile specimens, J. Braz. Soc. Mech. Sci. 26, 190-199 (2004).

[2] P.G. Kossakowski, W. Wciślik, Experimental determination and application of critical void volume fraction $f_{c}$ for S235JR steel subjected to multi-axial stress state, in: T. Łodygowski, J. Rakowski, P. Litewka (Eds.), Recent Advances in Computational Mechanics, 303-309, CRC Press/Balkema, London, 2014.

[3] P.G. Kossakowski, An analysis of the load-carrying capacity of elements subjected to complex stress states with a focus on the microstructural failure, Arch. Civ. Mech. Eng. 10, 15-39 (2010).

[4] P.G. Kossakowski, Microstructural failure criteria for S235JR steel subjected to spatial stress states, Arch. Civ. Mech. Eng. 15, 195-205 (2015).

[5] L.M. Kachanov, Time of the rupture process under creep conditions, Izvestiia Akademii Nauk SSSR, Otdelenie Teckhnicheskikh Nauk 8, 26-31 (1958).

[6] A.L. Gurson, Continuum theory of ductile rupture by void nucleation and growth: Part I - Yield criteria and flow rules for porous ductile media, J. Eng. Mater-T. ASME 99, 2-15 (1977).

[7] V. Tvergaard, Influence of voids on shear band instabilities under plane strain conditions, Int. J. Fracture 17, 389-407 (1981).

[8] V. Tvergaard, A. Needleman, Analysis of the cup-cone fracture in a round tensile bar, Acta Metall. 32, 157-169 (1984).

[9] V. Tvergaard, Material failure by void growth to coalescence, Adv. Appl. Mech. 27, 83-151 (1989).

[10] J. Faleskog, X. Gao, C.F. Shih, Cell model for nonlinear fracture analysis - I. Micromechanics calibration, Int. J. Fracture 89, 355373 (1998).

[11] I.I. Cuesta, J.M. Alegre, R. Lacalle, Determination of the GursonTvergaard damage model parameters for simulating small punch tests, Fatigue Fract. Eng. M. 33, 703-713 (2010).

[12] Z.L. Zhang, C. Thaulow, J. Ødegård, A Complete Gurson model approach for ductile fracture, Eng. Fract. Mech. 67, 155-168 (2000). 
[13] S. Aoki, K. Amaya, M. Sahashi, T. Nakamura, Identification of Gurson's material constants by using Kalman filter, Comput. Mech. 19, 501-506 (1997).

[14] M. Springmann, M. Kuna, Identification of material parameters of the Gurson-Tvergaard-Needleman model by combined experimental and numerical techniques, Comp. Mater. Sci. 32, 544-552 (2005).

[15] J. Zhong, T. Xu, K. Guan, B. Zou, Determination of Ductile Damage Parameters Using Hybrid Particle Swarm Optimization, Exp. Mech. 56, 945-955 (2016).

[16] W. Wciślik, Numerical determination of critical void nucleation strain in the Gurson-Tvergaard-Needleman porous material model for low stress state triaxiality ratio, Proceeding of METAL 2014: 23rd International Conference on Metallurgy and Materials, Brno, 794-800 (2014).
[17] P.G. Kossakowski, Stress Modified Critical Strain criterion for S235JR steel at low initial stress triaxiality, J. Theor. Appl. Mech. 52, 995-1006 (2014).

[18] P.G. Kossakowski, An analysis of the Tvergaard parameters at low initial stress triaxiality for S235JR steel, Pol. Marit. Res. 21, 100-107 (2014).

[19] P.G. Kossakowski, W. Wciślik, Effect of critical void volume fraction $f_{F}$ on results of ductile fracture simulation for S235JR steel under multi-axial stress states, Key Eng. Mat. 598, 113-118 (2014).

[20] W. Wciślik, Experimental determination of critical void volume fraction $f_{F}$ for the Gurson Tvergaard Needleman (GTN) model, Structural Integrity Procedia 2, 1676-1683 (2016).

[21] PN-EN 10025-2:2007 Hot-rolled structural steel. Part 2-Technical delivery conditions for non-alloy structural steels. 